\title{
Organic-inorganic hybrid coatings containing phosphorus precursors prepared by sol- gel on Ti6Al4V alloy: Electrochemical and in-vitro biocompatibility evaluation
}

A.A. El hadad, ${ }^{\text {a b }}{ }^{\text {F }}$.R. García-Galván, ${ }^{\text {a c c }}$ M.A. Mezour, ${ }^{\text {d }}$ G.J. Hickman, ${ }^{\text {b }}$ I.E. Soliman, ${ }^{\text {e A. }}$ Jiménez-Morales, ${ }^{\mathrm{f}}$ V. Barranco, ${ }^{\mathrm{a}}$ J.C. Galván ${ }^{\mathrm{a}^{*}}$ and C.C. Perry ${ }^{\mathrm{b}^{*}}$

${ }^{a}$ Centro Nacional de Investigaciones Metalúrgicas (CSIC), Madrid, Spain. E-mail: jcgalvan@cenim.csic.es

${ }^{b}$ Interdisciplinary Biomedical Research Centre, School of Science and Technology, Nottingham Trent University, Nottingham, NG11 8NS, UK. E-mail:

Carole.Perry@ntu.ac.uk

${ }^{c}$ Escuela de Arquitectura, Ingeniería y Diseño, Universidad Europea de Madrid, Villaviciosa de Odón, Madrid, Spain

${ }^{d}$ Faculty of Dentistry, McGill University, Montreal QC, Canada

${ }^{e}$ Biophysics Branch, Faculty of Science, Al-Azhar University, Nasr City, Cairo, Egypt

${ }^{f}$ Materials Science and Engineering and Chemical Engineering, Carlos III University of Madrid, Leganés (Madrid) Spain

\begin{abstract}
The durability and long-term success of metallic implants are enhanced through the molecular scale design of biocompatible and corrosion resistant surface coatings. To pursue this hypothesis, we have developed a new class of organic-inorganic (O-I) hybrid nanocomposite coatings based on tetramethylorthosilicate (TMOS) and $\gamma$ methacryloxypropyltrimethoxysilane (MAPTMS) as organofunctional alkoxysilanes precursors and dimethyltrimethylsilylphosphite (DMTMSP) as a phosphorus precursor. Addition of DMTMSP to TMOS-MAPTMS hybrids increased the extent of intermolecular condensation and cross-linking observed. Both normal human osteoblast in-vitro biocompatibility and corrosion resistance were enhanced in coatings containing DMTMSP. Though increasing phosphorous content correlated with biocompatibility, a compromise in the amount of phosphorus incorporated would be required if corrosion resistance was the most desirable parameter for optimization, at least for single coat systems. Evaluation of the electrochemical behaviour and the in-vitro biocompatibility show that films prepared using these materials by dip coating onto Ti6Al4V alloys offer a promising alternative to simpler coatings and wholly metallic prostheses.
\end{abstract}

Keywords: Organic-inorganic hybrid, Dimethyltrimethylsilylphosphite, Sol-gel coatings, Electrochemical corrosion resistance, In-vitro biocompatibility.

*Corresponding authors: carole.perry@ntu.ac.uk (Prof C. C. Perry), jcgalvan@cenim.csic.es (Dr J. C. Galván) 


\section{Introduction}

Bone grafts are used as a filler and scaffold to facilitate bone formation and promote wound healing. Today, bone grafting is one of the most commonly used surgical methods to augment bone regeneration. In the USA alone, the number of bone graft procedures approximates 500,000 per annum [1]. About $90 \%$ of these cases involve the use of autografts or allografts, the two "gold-standards" in the field [1]. However, the usage of autografts is expensive, and often associated with donor-site morbidity, whereas allografts introduce the risk of viral transformation and infection and can induce immunological rejection by the host [2]. To overcome these limitations, significant effort has been devoted to developing synthetic substitutes for bone implants. An ideal implant is required to be biocompatible, osteoconductive, bioactive and have similar mechanical properties to natural bone [3].

Titanium alloys such as Ti6Al4V are widely used as implants for orthopaedic and dental applications $[4,5]$. However, such implants take several months to integrate with the bone tissue. An innovative and emerging method to solve this problem consists of coating metallic substrates with a bioactive and corrosion resistant film. Several coating techniques have been adopted to improve the corrosion resistance of Ti6Al4V alloys, including plasma spraying [6], chemical conversion [7], atomic layer deposition [8] and the sol-gel method [9]. Of the above, the sol-gel technique has attracted considerable interest, since it provides a relatively simple, inexpensive and low processing temperature approach for forming pure, and homogenous protective coatings and thin films on various metallic materials including titanium and Ti6Al4V implants [10].

Organic-inorganic hybrid materials constitute a class of composite materials combining the properties of polymers and ceramics with unique characteristics arising from the synergy between the properties of both components and open up new possibilities for the design of materials with important applications in areas such as energy, environment, biology and medicine $[11,12]$. These unique characteristics can be exploited for the design and development of multifunctional coatings for corrosion protection and enhanced biocompatibility [13-17]. In this context, we have previously reported on the use of hydroxyapatite (HAp) and triethylphosphite (TEP) in inorganic and organic-inorganic hybrid coatings to improve biocompatibility and corrosion resistance of Ti6Al4V substrates [18-20]. The aim of this work is to evaluate the biocompatibility and corrosion protection behaviour of novel sol-gel coatings based on the modification of an MAPTMS/TMOS organic-inorganic hybrid with the phosphorous precursor dimethyltrimethylsilylphosphite (DMTMSP). It was anticipated that modification of the organopolysiloxane coating with DMTMSP would be more effective than 
the discrete hydroxyapatite particles or phosphorus ether (TEP) in terms of protection against corrosion and biocompatibility of metal coatings. In considering the inorganic components alone, silicon and phosphorus can be expected to act as network formers to overcome the problem of voids and pores that form during curing of the film because of water and ethanol evaporation. The modification of sol-gel coatings with phosphorus at molecular scale is an attractive goal, not just for corrosion protection applications but also for many biological processes, including osteoblast proliferation [20]. Coatings containing phosphorous additives could enhance biocompatibility through adsorption of physiological proteins. We believe that this study will add important new information to the growing body of knowledge on engineering rapid implant integration within the body.

\section{Materials \& Methods}

\section{Preparation of the Ti6Al4V alloy substrates}

Ti6Al4V disks of two sizes ( $2 \mathrm{~cm}$ diameter x $0.4 \mathrm{~cm}$ thickness and $0.9 \mathrm{~cm}$ x $0.4 \mathrm{~cm}$ ) were used in the study. The surfaces were ground with silicon carbide abrasives going from 320 to 2000 \# grit size. Disks were rinsed in $\mathrm{ddH}_{2} \mathrm{O}$, cleaned in an EtOH ultrasonic bath for $10 \mathrm{~min}$ and stored in a desiccator until use.

\section{Synthesis of organic-inorganic hybrids}

The organic-inorganic hybrid sol was prepared starting from a mixture of $\gamma$ methacryloxypropyltrimethoxysilane (MAPTMS, Aldrich, 98\%) and tetramethoxysilane (TMOS, Aldrich 98\%) at a molar ratio of 4:1. Ethanol (EtOH; absolute grade, Carlo Erba) and water (Elga, Maxima Ultra-Pure Water model, $18.2 \mathrm{M} \Omega \cdot \mathrm{cm}$ ) were used as solvents with MAPTMS hydrolysed with $\mathrm{H}_{2} \mathrm{O}$ through stirring, mixed with TMOS vigorously and stirred (700 rpm for $4 \mathrm{~h}$ ). The molar ratio silane (MAPTMS+TMOS)/water/ethanol was 1:3:3. Finally, the phosphorous precursor dimethyltrimethylsilylphosphite (DMTMSP, Fluka, 98\%) was added to the sol at a volumetric ratio of 0.3, 0.6 and $0.9 \mathrm{~mL}$ DMTMSP per $20 \mathrm{~mL}$ of the silane mixture (MAPTMS+TMOS). This corresponded to MAPTMS+TMOS / DMTMSP molar ratios between 1:0.03, 1:0.07 and 1:0.10 respectively. The mixture was stirred at $700 \mathrm{rpm}$ for $12 \mathrm{~h}$ at room temperature.

Deposition of the coatings

After synthesis, the hybrid sols were immediately deposited on the Ti6Al4V prepared surfaces by dip coating. Coatings were produced at a constant withdrawal rate of $9 \mathrm{~cm} \mathrm{~min}^{-1}$, under controlled environmental conditions $\left(25^{\circ} \mathrm{C}\right.$ and $35 \%$ relative humidity). The resulting coated 
Ti6Al4V samples were dried for $2 \mathrm{~h}$ at $120^{\circ} \mathrm{C}$ in air to enable densification and consolidation of the coatings.

A set of double-layer hybrid sol-gel coatings was also prepared to obtain tailored coatings with complementary properties, that is; an inner layer with barrier properties and an outer layer with biocompatibility properties through adsorption of physiological proteins. These coatings were prepared by repeating the immersion deposition method described above twice, performing the same thermal treatment after each layer to obtain the stabilized films. The deposition of the second layer filled the voids and pores that form during curing of the first layer due to water and ethanol evaporation. In this way, the inner layer with less porosity acts as a better barrier against the diffusion of toxic ions from the Ti6Al4V alloy surface to the physiological body fluid and, the outer layer with higher porosity is expected to enhance biocompatibility of the resulting double-layer hybrid sol-gel coatings.

\section{Characterization of hybrid coating composition, wettability, surface morphology and thickness.}

Thermal characterization was performed with a SETARAM DTA-TG SETSYS Evolution1750. The sample $(5 \mathrm{mg})$ and the reference material $\left(\alpha-\mathrm{Al}_{2} \mathrm{O}_{3}\right)$ were heated in air from room temperature to $900^{\circ} \mathrm{C}$ at $20^{\circ} \mathrm{C} \mathrm{min}^{-1}$. A Nicolet Magna IR 550 was used to obtain Attenuated Total Reflectance-Fourier Transform Infrared (ATR-FTIR) spectra of the cured hybrid coatings. Spectra (400 and $4000 \mathrm{~cm}^{-1}$, with a resolution of $4 \mathrm{~cm}^{-1}$ ) were recorded at room temperature with 8 scans accumulated per spectra.

A Bruker AVANCE-400 nuclear magnetic resonance (NMR) spectrometer (9.4 Tesla external field) was used to perform ${ }^{29} \mathrm{Si}$ magic angle spinning (MAS) at $79.49 \mathrm{MHz}$. Measurements were performed at $20^{\circ} \mathrm{C}$ and samples spun at $10 \mathrm{kHz}$ around the magic angle $\left(54^{\circ} 44^{\prime}\right.$ with respect to the magnetic field). Spectra (400 accumulated scans) with single pulse sequences were obtained after excitation with a $\pi / 2$ pulse length of $5 \mu \mathrm{s}$, and recycle delay of $10 \mathrm{sec}$. Deconvolution to determine different components and their contributions was performed in WINFIT, ${ }^{29} \mathrm{Si}$ chemical shift values are relative to $\mathrm{Si}\left(\mathrm{CH}_{3}\right)_{4}$.

Water contact angle was measuring with an OCA-15 Plus controlled with SCA20 software from Data Physics and supplied by Neurtek SA (Spain). The sessile drop method was used with 3 drops $(2 \mu \mathrm{L})$ measured per sample, measurements were taken immediately after positioning of the droplet. This process was repeated 3 times to allow a mean and standard deviation to be calculated. 
Surface morphology of coatings was examined by scanning electron microscope (SEM). Micrographs of $\mathrm{Au}$ coated specimens were obtained from a JEOL 6500F operating at an acceleration voltage of $15 \mathrm{kV}$. Energy dispersive X-ray analysis (EDXa) of carbon-coated specimens provided the elemental composition of the coatings.

The thickness of the sol-gel films deposited onto Ti6Al4V substrates were measured by using a Dektak 6M-Veeco stylus profiler accompanied with Dektak 32 software. The coating thickness was measured on half coated samples. Linear scans (1 $\mathrm{mm}$ in length) were used to measure the difference or step produced between the uncoated and coated surface of the sample. For statistical analysis three different areas of each film were studied and the results derived from coating thickness were expressed as a mean \pm standard deviation.

\section{In-vitro proliferation and adhesion of NHOst cultures on hybrid coatings}

Tissue culture was performed in vitro using normal human osteoblasts (NHOst, Lonza, UK) using the media, supplements and procedures recommended by the supplier. Tissue culture plastics were supplied by Sarstedt Inc., UK. Cell viability on coated and untreated Ti6Al4V substrates was measured with the neutral-red assay [21]. Substrates (2 cm diameter) were sterilised with methanol, in 6 well plates these were seeded 2500 cells per $\mathrm{cm}^{2}$ and cultured as normal. At day 7 the medium was replaced with RPMI-1640 (Lonza, UK) containing 0.01\% neutral red (Sigma-Aldrich, UK) and incubated for $2 \mathrm{~h}$. Discs were rinsed with Dulbecco's phosphate buffered saline (DPBS) and de-stain (1\% glacial acetic acid, 50\% EtOH) added. Plates were covered and shaken for $20 \mathrm{~min}$ to extract the dye and absorbance $(540 \mathrm{~nm})$ of the de-stain solution measured by plate reader (Tecan, UK). The assay was repeated 3 times in triplicate, disks without cells were used to control for non-specific dye absorption. Assay data was assessed using GraphPad Prism v.8.0.1, using a non-parametric Kruskal-Wallis test of oneway ANOVA with a Dunn's multiple pairwise comparison. A confidence level of 0.05 was used and the assumption of normality was assessed in each case. Error bars represent standard deviation.

NHOst f-actin cytoskeleton, nuclei and focal adhesion were visualised by fluorescence microscopy using an Olympus DP71 microscope. NHOst (2500 cells per $\mathrm{cm}^{2}$ ) were cultured as normal on $0.9 \mathrm{~mm}$ substrates. On day 7 , the media was aspirated, and cells fixed (4\% paraformaldehyde) and blocked (10\% BSA fraction IV in DPBS with 0.1\% TWEEN-20). Factin was visualised with a unit of Alexa Fluor® 568 phalloidin (Invitrogen, UK), focal adhesion sites with monoclonal mouse anti-human vinculin (clone hVIN-1) IgG1 (SigmaAldrich, UK) diluted to 1:1000 with Alexa Fluor ${ }^{\circledR} 488$ conjugated goat anti-mouse IgG 
(Invitrogen, UK) secondary at 1:1500. Staining was done for $1 \mathrm{~h}$ in blocking solution with washes between and after with DPBS with $0.1 \%$ TWEEN-20. Vectashield mounting medium (Vector Laboratories, USA) was used to visualise cell nuclei.

\section{Electrochemical impedance spectroscopy of hybrid coatings to determine corrosion protection behaviour}

The influence of DMTMSP on the corrosion protection behaviour of the organic-inorganic hybrid/Ti6A14V system was evaluated in an electrochemical cell filled with Kokubo's simulated body fluid (SBF; pH 7.4) [22]. An AutoLab EcoChemie PGSTAT30 (EcoChemie, Utrecht, Netherlands) potentiostat/galvanostat with FRA2 frequency response analyser was used to perform electrochemical impedance spectroscopy (EIS). A three-electrode setup in which the working electrode was the $2.14 \mathrm{~cm}^{2}$ sample, reference and counter electrodes were respectively a saturated calomel electrode (SCE) and a graphite sheet. Logarithmic frequency scans $\left(10^{5}-10^{-3} \mathrm{~Hz}\right)$ applying sinusoidal wave perturbations $\pm 10 \mathrm{mV}$ in amplitude were performed with 5 impedance points registered per frequency decade. EIS measurements of the O-I hybrid/Ti6Al4V were made at the open circuit potential (OCP) with variable immersion time at $37^{\circ} \mathrm{C}$ in $\mathrm{SBF}$. Impedance data were analysed in ZView 3.1c (Scribner Associates Inc., NC, USA) [23].

\section{Results}

\section{Characterization of hybrid organic-inorganic MAPTMS-TMOS-DMTMSP hybrid films} Thermogravimetric analysis of MAPTMS/TMOS hybrid modified with DMTMSP (22 - 900 ${ }^{\circ} \mathrm{C}$ ) is shown in fig. $1 \mathrm{~A}$. All hybrids exhibit a first weight loss at $30-223{ }^{\circ} \mathrm{C}$ that is assigned to the loss of residual water [24]. The pronounced weight loss at $223-439{ }^{\circ} \mathrm{C}$ is attributed to the combustion of the organic components [25]. These findings showed that the optimal curing temperature of the deposited hybrid films should not exceed $120{ }^{\circ} \mathrm{C}$ to avoid decomposition of the organic component in the hybrid. Further weight loss takes place at $439-679{ }^{\circ} \mathrm{C}$ and reaches a plateau at $640{ }^{\circ} \mathrm{C}$ indicating the point of complete loss of organic material [26]. 

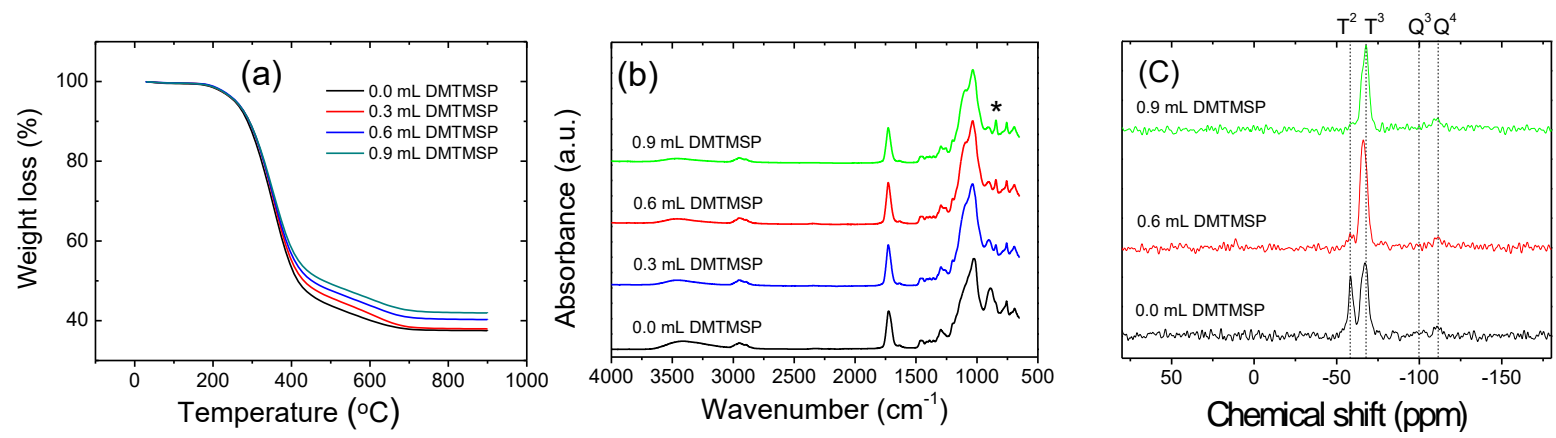

Figure 1. (a) TGA of the prepared MAPTMS/TMOS hybrids containing increasing amounts of DMTMSP. (b) ATR-IR spectra of the MAPTMS/TMOS/ DMTMSP -Ti6A14V system for coatings containing different content of DMTMSP. (c) Solid state ${ }^{29} \mathrm{Si}-\mathrm{NMR}$ spectra of

MAPTMS/TMOS silane hybrids containing 0.0, 0.6 and $0.9 \mathrm{~mL}$ of DMTMSP.

Attenuated Total Reflectance-Fourier Transform Infrared Spectroscopy (ATR-FTIR) revealed the structural changes in MAPTMS/TMOS hybrid upon addition of the DMTMSP precursor (fig. 1B). ATR-FTIR spectra of pure siloxane and siloxane/DMTMSP hybrid coatings revealed bands at $1032 \mathrm{~cm}^{-1}, 1732 \mathrm{~cm}^{-1}, 2938 \mathrm{~cm}^{-1}$ and $3405 \mathrm{~cm}^{-1}$ attributed to siloxane (Si-O-Si), carbonyl $(\mathrm{C}=\mathrm{O}),-\mathrm{CH}_{2}-$ asymmetric stretching, and $-\mathrm{OH}$ bonds respectively [27]. The control sample showed the Si-OH bands at $917 \mathrm{~cm}^{-1}$ which decreased in intensity as DMTMSP content increased (fig. 1B) suggesting an increase in the hydrophobicity of the hybrid network [28]. The spectra of the DMTMSP containing films show additional bands at $1069 \mathrm{~cm}^{-1}$ and $833 \mathrm{~cm}^{-}$ ${ }^{1}$ ascribed to Si-O-P stretching and bending respectively [29]. These bands are characteristic for the DMTMSP bonding to the siloxane function groups within the hybrid network.

${ }^{29} \mathrm{Si}-\mathrm{NMR}$ spectroscopy provided further insights into the cross-linking within the organosilica matrix (MAPTMS/TMOS/DMTMSP) (fig. 1C). The chemical shift of the silicon atom in the organosilica matrix is represented using the terminology $\mathrm{Q}^{\mathrm{n}}$ and $\mathrm{T}^{\mathrm{n}}$, where $\mathrm{n}$ represents the number of oxygen bridges for $\mathrm{R}-\mathrm{Si}(\mathrm{OH})_{3}(\mathrm{~T})$ and $\mathrm{Si}(\mathrm{OH})_{4}(\mathrm{Q})$ species [27]. The spectrum of the control sample shows four peaks at $-60,-68,-100$ and -111 ppm (fig. 1C), corresponding to the $\mathrm{T}^{2}, \mathrm{~T}^{3}, \mathrm{Q}^{3}$ and $\mathrm{Q}^{4}$ units respectively. The presence of the $\mathrm{Q}^{3}$ and $\mathrm{Q}^{4}$ units in the spectra of all samples is a result of the TMOS condensation that resulted from thermal curing of the samples for $2 \mathrm{~h}$ at $120^{\circ} \mathrm{C}$. The MAPTMS/TMOS/DMTMSP spectra showed a decrease in the $\mathrm{T}^{2}$ peak at $-60 \mathrm{ppm}$, together with an increase in the $\mathrm{T}^{3}$ peak at $-68 \mathrm{ppm}$ as the content of DMTMSP increased. This was attributed to the increase in cross-linking in presence of DMTMSP, as DMTMSP promoted the condensation reaction of the silanol groups. The relative peak ratio (in area) of $\mathrm{T}^{3} / \mathrm{T}^{2}$ signals is $1.9,8.1$ and 16.3 for the control and hybrids containing 
0.3 and $0.9 \mathrm{~mL}$ DMTMSP respectively. This confirms that the hybrid containing $0.9 \mathrm{~mL}$ DMTMSP presents the highest degree of cross-linking.

Scanning electron (SEM) micrographs of the control and hybrid coatings showed the formation of uniform, homogeneous and crack free protective films on the substrates (fig. S1). Titanium (Ti) and Aluminium (Al) were observed in the EDX spectra of the MAPTMS/TMOS-Ti6Al4V system. In contrast, only Silica ( $\mathrm{Si}$ ) and Phosphorus (P) were detected on MAPTMS/TMOS/DMTMSP-Ti6Al4V systems suggesting the incorporation of the DMTMSP in the organosilica matrix and the generation of a thicker or denser hybrid film.

The sessile drop method was used to characterize the wettability of the prepared films. The measured water contact angles were $67 \pm 1^{\circ}, 75 \pm 2^{\circ}, 76 \pm 1^{\circ}$ and $79 \pm 1^{\circ}$ for the control film, and the films containing 0.3, 0.6, and $0.9 \mathrm{~mL}$ DMTMSP respectively. The increase in contact angle with the increase in DMTMSP concentration is supportive evidence for the incorporation of DMTMSP in the hybrids. This agreed with the results obtained by ATR-IR and ${ }^{29} \mathrm{Si}-\mathrm{NMR}$. Fig. 2 shows the variation of coating thickness as a function of DMTSP content. The average of three measurements was taking as the final value for each sample, as expected, the coating thickness increased as the amount of DMTSP increased.

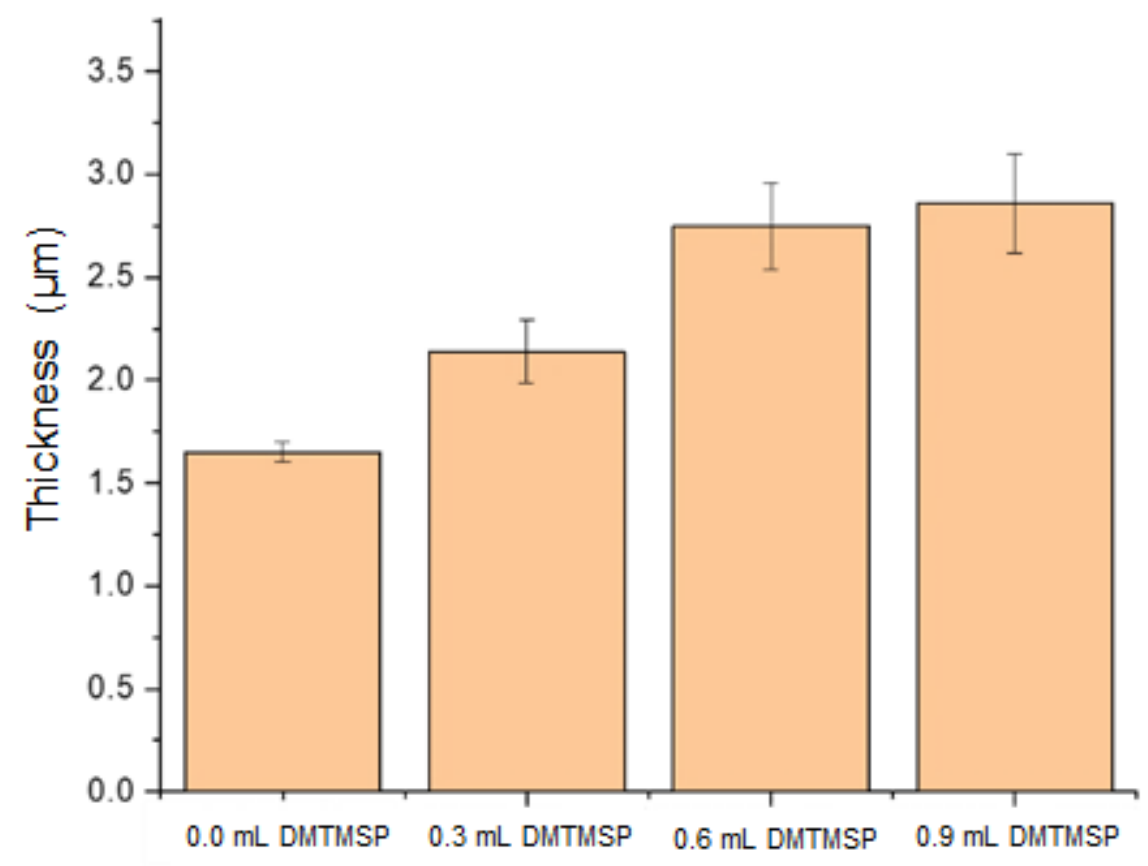

Figure 2. Variation in the thickness of the MAPTMS/TMOS silane hybrid coatings as a function of the DMTMSP content (0.0, 0.3, 0.6 and $0.9 \mathrm{~mL})$. 


\section{Influence on NHOst viability and adhesion}

The effect of MAPTMS/TMOS/DMTMSP films on the proliferation of normal human osteoblasts (NHOst) was studied by the neutral red uptake assay. Fig. 3a shows the osteoblast viability on the un-coated and coated Ti6Al4V alloy after 7 days in culture under standard conditions.

At the seventh day culture interval the measured absorbance values for NHOst cells cultured on coated surfaces were significantly higher than those cultured on the uncoated control surfaces, suggesting a coating dependant enhancement of cell viability and proliferation. This surface dependant enhancement in cell viability was also observed for the DMTMSP containing films and further increases in viability correlated with increasing content of DMTMSP in the hybrid coatings. The enhancements observed for the DMTMSP were significant in comparison with the Ti6Al4V alloy and the MAPTMS/TMOS coated surfaces. This result shows a significant improvement in biocompatibility for NHOst cells can be obtained for Ti6Al4V alloys using DMTMSP containing films compared to the MAPTMS/TMOS coatings and to the uncoated substrate.

The cell morphology of adherent cells cultured for 7 days on the uncoated and coated Ti6Al4V substrates with various coating compositions was examined using fluorescence microscopy (fig. 3b). 

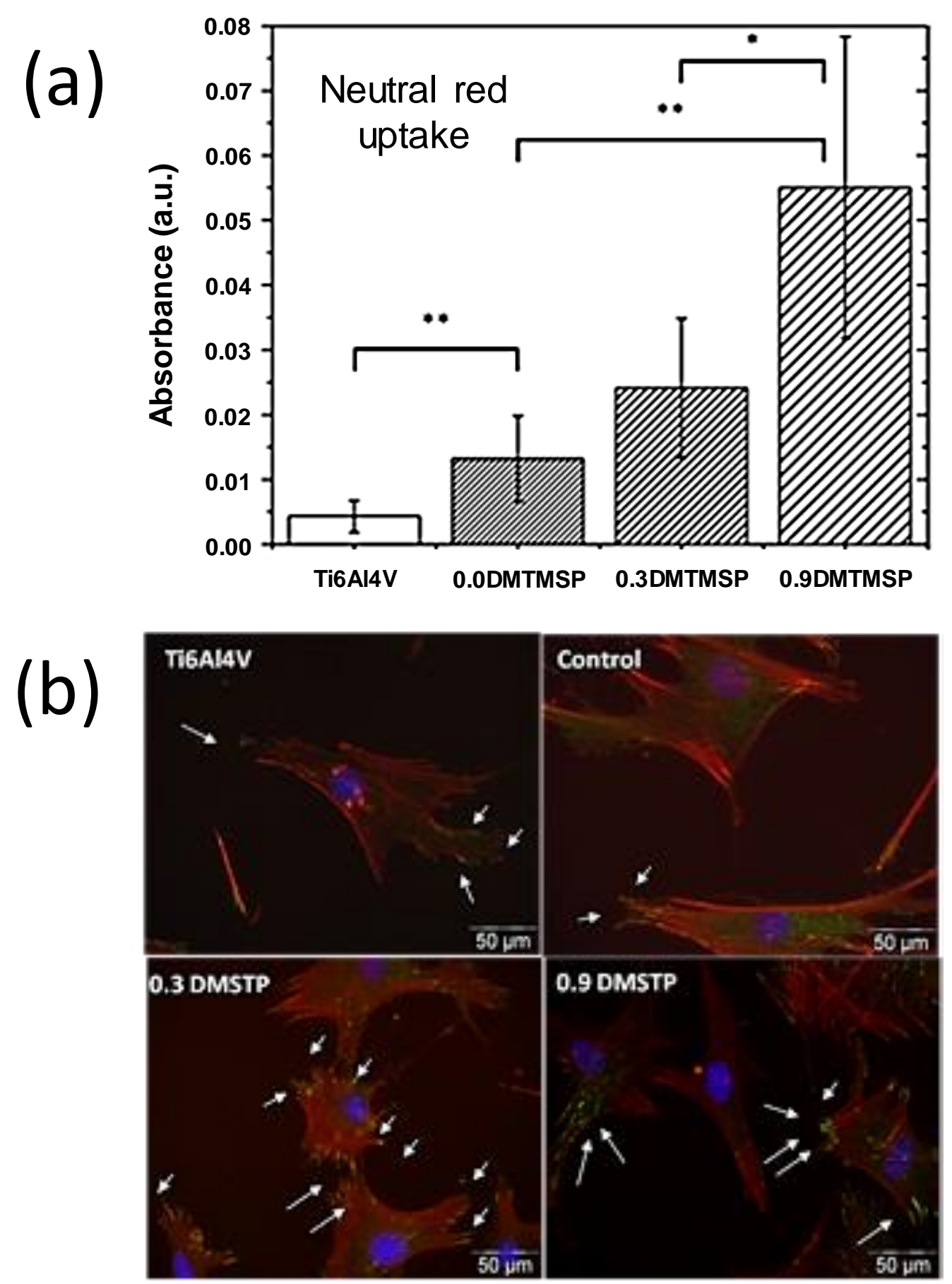

Figure 3. (a) Neutral red proliferation/cytotoxicity assay for NHOst cultured on un-coated Ti6Al4V, MAPTMS/TMOS-Ti6Al4V system (control) and silane hybrid coatings containing DMTMSP (0.3 and $0.9 \mathrm{~mL}$ ) after a 7-day period. (b) Fluorescence micrographs of NHOst cells growing on un-coated Ti6Al4V and coated surfaces and stained for the presence of vinculin (green), f-actin (red) and nuclei (blue). Arrows highlight regions where focal adhesion is observed between cell and surface.

Osteoblast cells were observed to have adhered and spread both on the uncoated Ti6Al4V alloy, the Ti6A14V coated with MAPTMS/TMOS unmodified films (control samples) and the 
MAPTMS/TMOS hybrid modified with DMTMSP (0.3 and $0.9 \mathrm{~mL})$. However, in terms of the number of adhered cells, number of focal adhesion contacts/extent of vinculin staining and factin fibre formation, this was observed to be higher on the coated surface rather than the bare alloy. The films containing DMTMSP also compared well to the uncoated sample, suggesting a better surface for integration with the osteoblast cells and that DMTMSP is not detrimental to the MAPTMS/TMOS coating (fig. 3b). In this case, the actin stress fibres and focal adhesion sites were more mature than for osteoblasts observed growing on the bare alloy and coatings without DMTMSP. The fluorescence observations correlated with the dye uptake assay, that on incorporation DMTMSP appears to improve the biocompatibility of the MAPTMS/TMOS coated alloys, at least in-vitro.

\section{Corrosion protection behaviour of MAPTMS-TMOS-DMTMSP hybrid films}

In-vitro corrosion and protection studies of the MAPTMS/TMOS/DMTMSP-Ti6A14V system immersed in Kokubo's simulated body fluid (SBF) were carried out by electrochemical impedance spectroscopy (EIS) measurements. Fig. 4 shows the experimental results of the impedance plots obtained for an uncoated Ti6Al4V sample and two MAPTMS/TMOS/DMTMSP (0.9 mL) -Ti6Al4V systems based on 1 and 2 coating layers respectively. The formulation of the top layer of the two-layer coating system has the same composition as the first layer and was applied following the same experimental procedure previously described (see Material and Methods). The impedance plots were recorded after 1 day of immersion in SBF.

In fig. $4 \mathrm{a}$ and $4 \mathrm{~b}$ the impedance data is represented by Nyquist diagrams. Fig. 4a shows the complete Nyquist plots for the entire frequency domain tested $\left(10^{5}-10^{-2} \mathrm{~Hz}\right)$. Fig. $4 \mathrm{~b}$ shows an enlarged view of the high frequency region of these Nyquist plots. In fig. $4 \mathrm{c}$ and fig. $4 \mathrm{~d}$ the same impedance data are displayed using the Bode representation. 

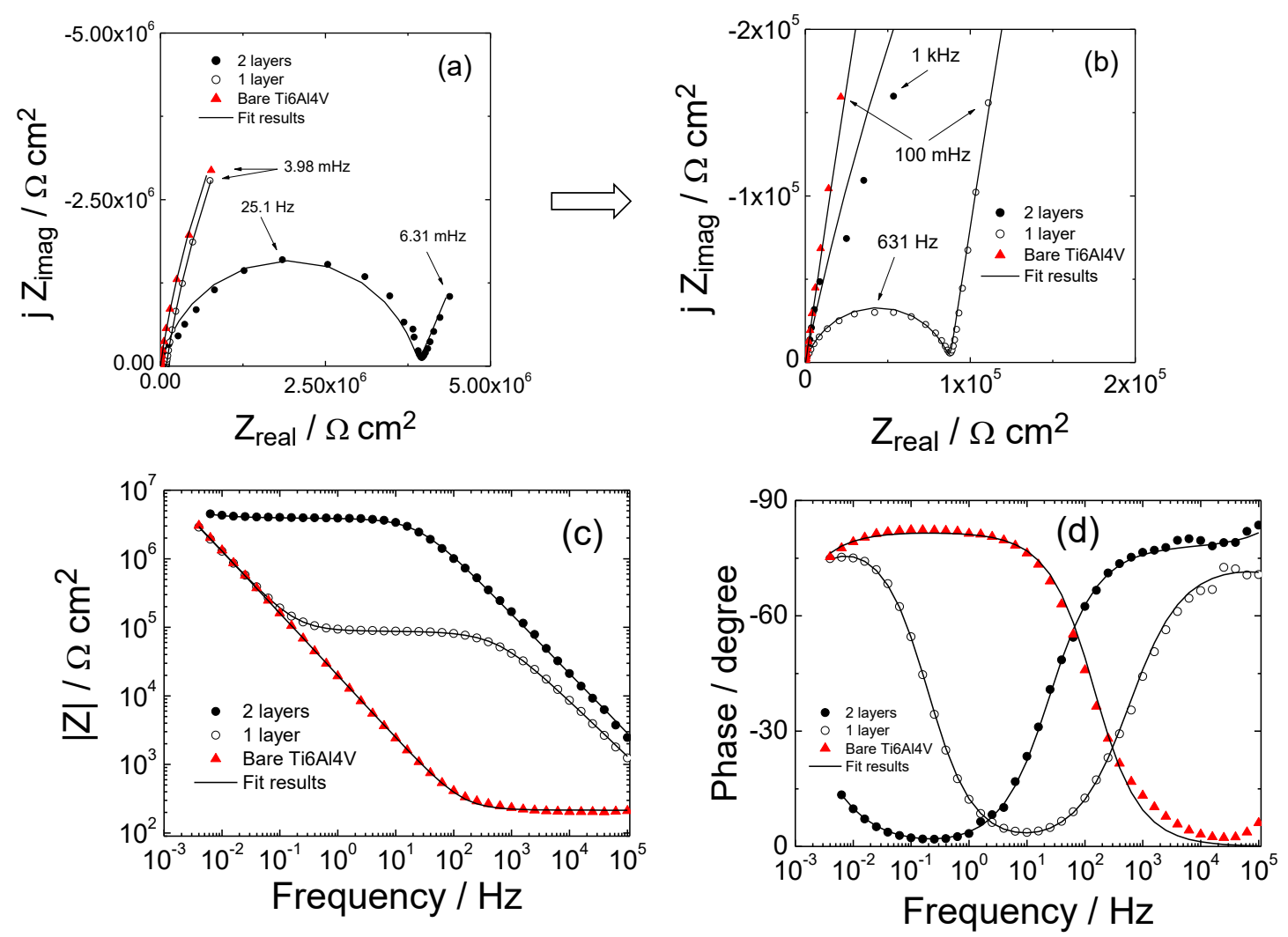

Figure 4. (a, b) Impedance Nyquist plots obtained for an uncoated Ti6Al4V sample and for two Ti6Al4V samples coated with one layer and two layers of the MAPTMS/TMOS silane mixture containing DMTMSP $(0.9 \mathrm{~mL})$. (c, d) The same impedance data in Bode representation. Immersion time in SBF: 1 day.

In order to analyse the impedance plots obtained for the i) uncoated Ti6Al4V sample ii) onelayer sol-gel/Ti6Al4V sample and iii) two-layer sol-gel/Ti6Al4V sample, three different equivalent circuits have been used, named ECC1, ECC2 and ECC3, one for each studied system respectively. Fig. 5 illustrates these equivalent circuits as defined below.

i) ECC1 has been used for studying the electrochemical behaviour of the uncoated Ti6Al4V sample. In this circuit the element Rs represents the resistance of the electrolyte, CPEdl is a constant phase element describing the non-ideal behaviour of the double layer capacitance $\left(\mathrm{C}_{\mathrm{dl}}\right)$ and, $R_{c t}$ is the charge transfer resistance at the electrolyte/Ti6Al4V electrode interface [30] ii) ECC2 has been used for studying the one-layer sol-gel/Ti6Al4V sample. In this circuit Rs represents the resistance of the electrolyte, $\mathrm{CPE}_{\text {coat }}$ is the constant phase element associated with the sol-gel coating capacitance $\left(\mathrm{C}_{\text {coat }}\right)$ and $\mathrm{R}_{\text {coat }}$ is the resistance of the electrolyte in the pores of the sol-gel coating. CPEdl is a constant phase element associated with the electrochemical double layer at the metal/electrolyte interface and $\mathrm{R}_{\mathrm{ct}}$ is the charge transfer 
resistance associated with the corrosive process both at the base of the pores of the sol-gel coating [31-33].

iii) ECC3 has been used for the two-layer sol-gel/Ti6Al4V samples. This was because for these systems, EEC2 produced inconsistent values for the charge transfer resistance associated with the corrosive process. Indeed, the $\mathrm{R}_{\mathrm{ct}}$ values obtained with EEC2 were higher than $1 \cdot 10^{20}$ $\mathrm{ohm} \cdot \mathrm{cm}^{2}$ with an associated error percentage higher that $100 \%$. That is to say, the $\mathrm{R}_{\mathrm{ct}}$ resistive component of the system approached infinite impedance $\left(\mathrm{R}_{\mathrm{ct}} \rightarrow \infty\right)$. This fact allows us to simplify the ECC2 equivalent circuit, which evolves to an ECC3 circuit with removal of the $\mathrm{R}_{\mathrm{ct}}$ element. In this circuit $\mathrm{R}_{\mathrm{s}}$ is the resistance of the electrolyte, $\mathrm{CPE}_{\mathrm{coat}}$ associated with the constant phase element of the sol-gel coating capacitance $\left(\mathrm{C}_{\text {coat }}\right)$ and $\mathrm{R}_{\text {coat }}$ is the resistance of the electrolyte in the pores of the sol-gel coating. The electrical element in series with the $\mathrm{R}_{\text {coat }}$ could be ascribed to a constant phase element $\left(\mathrm{CPE}_{\mathrm{dl}}\right)$ associated with the double layer capacitance at the metal/electrolyte interface at the base of the pores of the sol-gel coating $\left(\mathrm{C}_{\mathrm{dl}}\right)$. However, as it shown in table 1, the value of the parameter $\alpha_{\mathrm{dl}}$ associated with the CPE $\mathrm{dl}_{\mathrm{d}}$ element is 0.74 . This value is far from what is expected for a pure capacitor, which should tend to 1 .

Alternatively, instead of the CPEdl, a new electrical element $\mathrm{W}_{\mathrm{o}}$ can be introduced in the EEC3 equivalent circuit, which is associated with the Warburg diffusion phenomena of the electrolyte through the two-layer system. When the $\mathrm{W}_{\mathrm{o}}$ element is used in the EEC3 equivalent circuit to fit the results obtained for the two-layer sol-gel/Ti6Al4V sample after one day of immersion, values obtained for $\mathrm{W}_{\mathrm{o}}$ are: $4.14 \cdot 10^{6} \Omega \mathrm{cm}^{2}$ for $\mathrm{W}_{\mathrm{o}}-\mathrm{R}, 169.8 \mathrm{~s}^{\alpha} / \Omega \mathrm{cm}^{2}$ for $\mathrm{W}_{\mathrm{o}}-\mathrm{T}$ and 0.705 for $\mathrm{W}_{\mathrm{o}}-\mathrm{P}$. The $\mathrm{W}_{\mathrm{o}}-\mathrm{P}$ value is far from 0.5 , which is the value expected for a pure diffusive element. This electrical behaviour suggests that the electrical response of the $W_{o}$ and CPEdl elements can occur at the same frequency range and their corresponding time constants can overlap. For this reason, the fitting of the results can be performed with the same accuracy (low error percentage for each element and Chi-squared values below $10^{-3}$ ) using either the $\mathrm{W}_{\mathrm{o}}$ or $\mathrm{CPE}_{\mathrm{d}}$ element. Moreover, the values obtained for the sol-gel coating capacitance $\left(\mathrm{C}_{\text {coat }}\right)$ and coating resistance $\left(\mathrm{R}_{\text {coat }}\right)$ are the same regardless of using the $\mathrm{W}_{\mathrm{o}}$ electrical element associated with the Warburg diffusion impedance or the CPE $\mathrm{dl}_{\mathrm{d}}$ constant phase element in the EEC3 equivalent circuit (Table 1). 

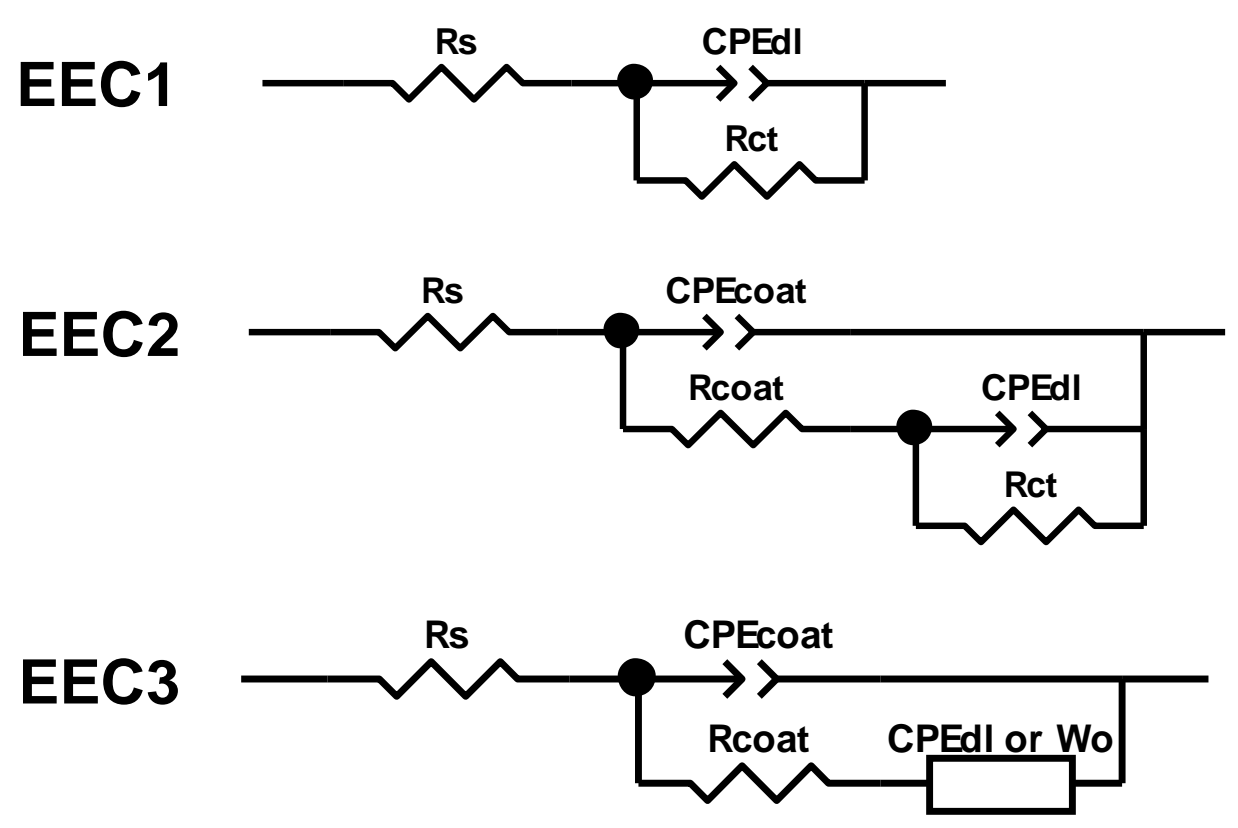

Figure 5. Equivalent circuits EEC1, EEC2 and EEC3 used for fitting and modelling the experimental impedance data of the studied systems.

Table 1 shows the values obtained for each electrical element of the equivalent circuit. It can be seen that the $\mathrm{R}_{\text {coat }}$ values obtained for MAPTMS/TMOS/DMTMSP-Ti6Al4V systems based on a single coating layer are low when compared to coatings with higher thickness. Although the one-layer system reduces ion release from the Ti6Al4V alloy to the physiological medium and improves biocompatibility, to improve the barrier prpperties, samples coated with two layers of the same composition have also been studied. Table 1 shows that the $R_{\text {coat }}$ values increased from $8.78 \cdot 10^{4}$ up to $3.88 \cdot 10^{6} \mathrm{ohm} \cdot \mathrm{cm}^{2}$ for the two-layer system. Additionally, the parameter $\mathrm{Q}_{\text {coat }}$ associated the constant phase element of the coating ( $\left.\mathrm{CPE}_{\text {coat }}\right)$ exhibits favourable variations from the point of view of the corrosion protection behaviour, decreasing in value one order of magnitude when a second sol-gel layer is applied.

Table 1. Calculated values for each element of the equivalent circuits shown in fig. 5 and chisquared values $\left(\chi^{2}\right)$ obtained in the fitting procedures for an uncoated Ti6Al4V sample and for

two MAPTMS/ TMOS/ DMTMSP-Ti6Al4V systems based on coatings of 1 and 2 layers respectively. Immersion time in SBF: 1 day. DMTMSP/ silane hybrid volumetric ratio $=0.9$ $\mathrm{mL} / 20 \mathrm{~mL}$

\begin{tabular}{l|c|c|c}
\hline Sample & Uncoated Ti6Al4V & $\begin{array}{c}\text { Coated Ti6Al4V } \\
(1 \text { layer })\end{array}$ & $\begin{array}{c}\text { Coated Ti6Al4V } \\
(2 \text { layers })\end{array}$ \\
\hline $\begin{array}{l}\text { Equivalent circuit } \\
\text { Element }\end{array}$ & EEC1 & EEC2 & \multicolumn{2}{|c|}{ EEC3 } \\
Value Error \% & Value Error \% & Value Error \% \\
\hline
\end{tabular}




\begin{tabular}{|c|c|c|c|c|c|c|}
\hline$R_{s}\left(\Omega \cdot \mathrm{cm}^{2}\right)$ & $2.15 \cdot 10^{1}$ & 1.06 & $3.53 \cdot 10^{1}$ & 7.10 & $\begin{array}{c}3.53 \cdot 10^{1} \\
\text { (Fixed) }\end{array}$ & N/A \\
\hline$Q_{\text {coat }}\left(F \cdot s^{\alpha-1} / \mathrm{cm}^{2}\right)$ & - & - & $1.38 \cdot 10^{-8}$ & 3.83 & $3.19 \cdot 10^{-9}$ & 4.79 \\
\hline $\boldsymbol{\alpha}_{\text {coat }}$ & - & - & 0.82 & 0.44 & 0.87 & 0.57 \\
\hline$R_{\text {coat }}\left(\Omega \cdot \mathrm{cm}^{2}\right)$ & - & - & $8.78 \cdot 10^{4}$ & 0.57 & $3.90 \cdot 10^{6}$ & 1.80 \\
\hline$Q_{\text {dl }}\left(F \cdot s^{\alpha-1} / \mathrm{cm}^{2}\right)$ & $9.52 \cdot 10^{-6}$ & 0.90 & $9.61 \cdot 10^{-6}$ & 1.04 & $9.87 \cdot 10^{-6}$ & $3.70 \cdot 10^{1}$ \\
\hline $\boldsymbol{\alpha}_{\mathrm{dl}}$ & 0.91 & 0.27 & 0.90 & 0.50 & 0.74 & $1.52 \cdot 10^{1}$ \\
\hline $\mathbf{R}_{\text {ct }}\left(\Omega \cdot \mathbf{c m}^{2}\right)$ & $3.03 \cdot 10^{7}$ & $3.12 \cdot 10^{-1}$ & $3.21 \cdot 10^{7}$ & $2.19 \cdot 10^{1}$ & - & - \\
\hline$\chi^{2}$ & \multicolumn{2}{|c|}{$1.40 \cdot 10^{-3}$} & \multicolumn{2}{|c|}{$1.66 \cdot 10^{-3}$} & \multicolumn{2}{|c|}{$1.97 \cdot 10^{-2}$} \\
\hline
\end{tabular}

Fig. 6 shows the impedance plots obtained for MAPTMS/TMOS/DMTMSP-Ti6Al4V systems with different DMTMSP content and for an uncoated Ti6Al4V sample, after 1 day of immersion in SBF. Fig. 6a and fig. 6b show the Nyquist impedance plots (on two different scales). Fig. 6c and fig. 6d show the same impedance data represented as Bode plots. By comparing the impedance response obtained for the sol-gel coatings containing phosphorus with the impedance response of the phosphorus-free sol-gel films (blank samples), it is clear that the diameters of the high-frequency arcs (HFAs) of the DMTMSP sol-gel coatings are lower than HFA diameter obtained for the phosphorous free blank sol-gel coatings at 1 day of exposure in SBF (fig. 6b). This result indicates that the addition of DMTMSP to the MAPTMS/TMOS system does not improve the barrier properties of the obtained sol-gel coatings. Nevertheless, in long-term immersion tests (30 days) the DMTMSP containing films showed the best results (fig. 7). 

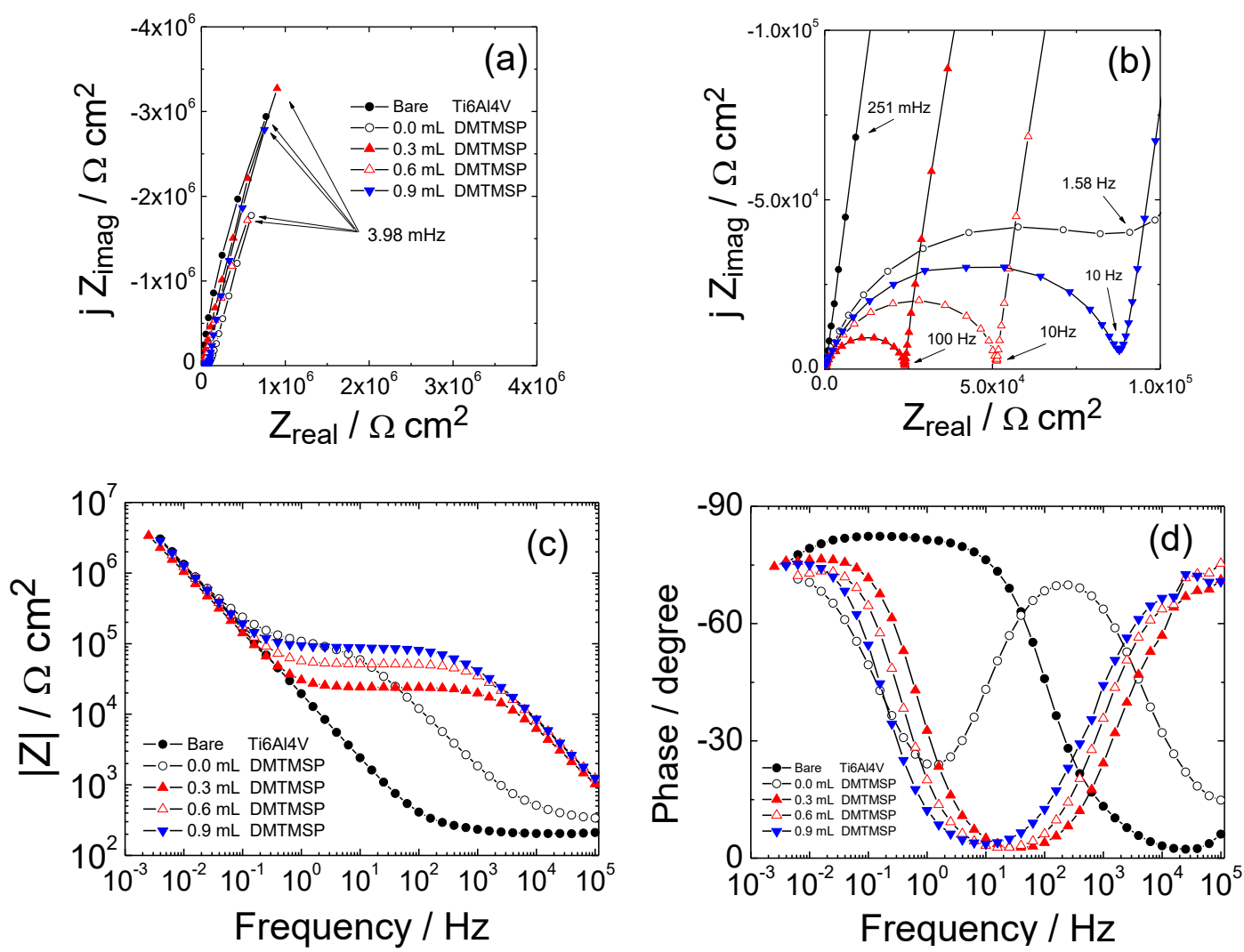

Figure 6. Nyquist plots, represented in two different scales [(a) and (b)] and Bode plots [(c) and (d)] obtained for an uncoated Ti6Al4V sample and Ti6Al4V samples coated with one layer of DMTMSP sol-gel thin films with different volumetric ratios of DMTMSP: $0 \mathrm{~mL}$ (blank sample), $0.3 \mathrm{~mL}, 0.6 \mathrm{~mL}$ and $0.9 \mathrm{~mL}$ per $20 \mathrm{~mL}$ of MAPTMS/TMOS silane mixture respectively. Electrolyte: SBF. Immersion time: 1 day.

Table 2 shows the values of the electrical elements of circuit equivalents associated to the high frequency arcs (HFA), that is; the high frequency resistance (RHFA), the constant phase element parameters ( $\mathrm{Q}_{\mathrm{HFA}}$ and $\left.\alpha_{\mathrm{HFA}}\right)$ and the coating capacitance $\left(\mathrm{C}_{\mathrm{HFA}}\right)$ as a function of the phosphorous content in the sol-gel coatings for systems of one layer. The chi-square $\left(\chi^{2}\right)$ obtained for the fit results is also shown. The capacitance values of the capacitor $\mathrm{C}_{\mathrm{HFA}}$ associated to the constant phase element $\mathrm{CPE}_{\mathrm{HAF}}$ have been calculated by using the following equation (1):

$$
C_{H F A}=\left[Q_{H F A} R_{H F A}^{\left(1-\alpha_{H F A}\right)}\right]^{\frac{1}{\alpha_{H F A}}}
$$

This equation is equivalent to equation (3) in the work of Hsu and Mansfeld, presented in terms of the characteristic angular frequency $\omega \max [34-36]$. 
Table 2. Values of the resistance, CPE parameters ( $Q$ and $\alpha$ ) and capacitance and chi-square associated to the high frequency arc (HFA) obtained for an uncoated Ti6Al4V sample and for MAPTMS/TMOS/DMTMSP-Ti6A14V systems based on coatings of one layer with different DMTMSP content. Electrolyte: SBF. Immersion time: 1 day.

\begin{tabular}{llllll}
\hline Sample & $\begin{array}{l}\mathbf{R}_{\mathbf{H F A}} \\
\left(\boldsymbol{\Omega} \cdot \mathbf{c m}^{\mathbf{2}}\right)\end{array}$ & $\begin{array}{l}\mathbf{Q}_{\text {HFA }} \\
\left(\mathbf{F} \cdot \mathbf{s}^{\boldsymbol{\alpha}-\mathbf{1}} \cdot \mathbf{c m}^{-\mathbf{2}}\right)\end{array}$ & $\boldsymbol{\alpha}_{\mathbf{H F A}}$ & $\begin{array}{l}\mathbf{C}_{\mathbf{H F A}} \\
\left(\mathbf{F} \cdot \mathbf{c m}^{-\mathbf{2}}\right)\end{array}$ & $\boldsymbol{\chi}^{\mathbf{2}}$ \\
\hline Uncoated Ti6A14V & $3.03 \cdot 10^{7}$ & $9.52 \cdot 10^{-6}$ & 0.91 & $1.67 \cdot 10^{-5}$ & $1.40 \cdot 10^{-3}$ \\
0.0 mL DMTMSP coating & $1.09 \cdot 10^{5}$ & $3.85 \cdot 10^{-7}$ & 0.83 & $2.02 \cdot 10^{-7}$ & $1.24 \cdot 10^{-3}$ \\
0.3 mL DMTMSP coating & $2.39 \cdot 10^{4}$ & $1.49 \cdot 10^{-8}$ & 0.83 & $2.93 \cdot 10^{-9}$ & $1.31 \cdot 10^{-3}$ \\
0.6 mL DMTMSP coating & $5.17 \cdot 10^{4}$ & $1.17 \cdot 10^{-8}$ & 0.90 & $5.13 \cdot 10^{-9}$ & $1.35 \cdot 10^{-3}$ \\
0.9 mL DMTMSP coating & $8.78 \cdot 10^{4}$ & $1.38 \cdot 10^{-8}$ & 0.82 & $3.16 \cdot 10^{-9}$ & $1.66 \cdot 10^{-3}$ \\
\hline
\end{tabular}

The behaviour of the $0.9 \mathrm{~mL}$ DMTMSP coated sample with immersion time over 30 days in SBF is shown in fig. 7 ( $a, b, c, d)$. For comparative purposes the behaviour of the $0.0 \mathrm{~mL}$ DMTMSP coating is included in fig. $7(\mathrm{a}, \mathrm{b})$. For the $0.9 \mathrm{~mL}$ DMTMSP coating sample, a continuous decrease of the electrolyte resistance in the coating pores $\left(\mathrm{R}_{\text {coat }}\right)$ for short-term immersion tests in SBF (0-15 days) (fig. 7a), and a continuous increase in the coating capacitance $\left(\mathrm{C}_{\text {coat }}\right)$ (fig. $7 \mathrm{~b}$ ). This behaviour is due to a decrease in the barrier properties allowing for an increase in water uptake into the coating with immersion time. An asymptotic slow decrease in the $\mathrm{R}_{\text {coat }}$ values and an anomalous decrease in the $\mathrm{C}_{\text {coat }}$ values for long-term immersion tests (15-30 days) can also be observed in fig. 7a and fig. $7 \mathrm{~b}$. This last behaviour could be related to the amount of water taken up by the coating and the interaction (e.g. swelling) of the coating polymer [37,38]. In contrast the values of the parameters associated with corrosion of the metal substrate and the electrochemical double layer on the base of the coating pores $\left(\mathrm{R}_{\mathrm{ct}}\right.$ and $\left.\mathrm{C}_{\mathrm{dl}}\right)$ remain nearly constant during the 30 days of immersion tests in SBF (fig. 7c and fig. 7d). These results indicate that the Ti6Al4V metallic substrate remains stable under the sol-gel coating over a long period in an SBF environment. 

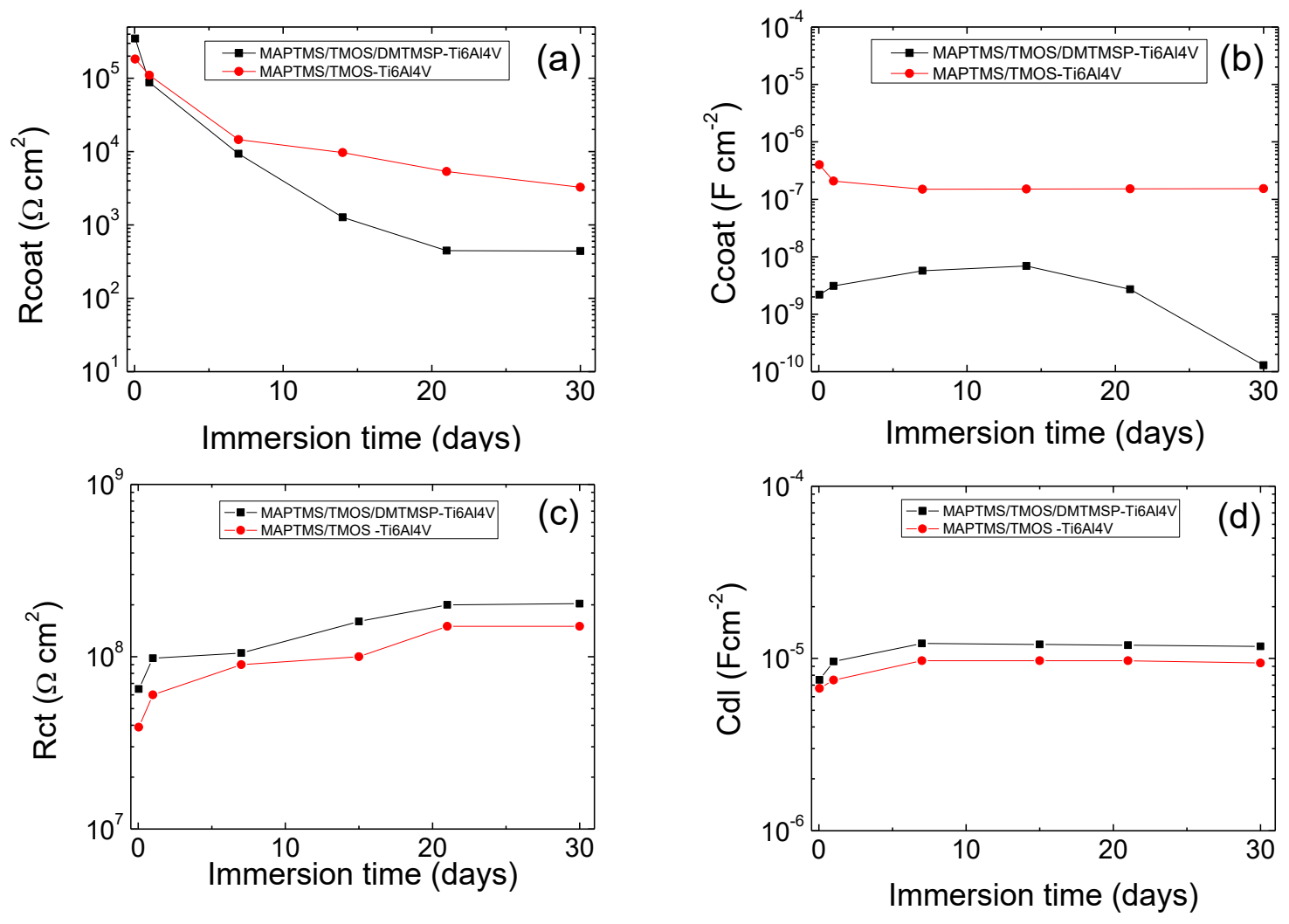

Figure 7. Evolution of the Rcoat (a), Ccoat (b), Rct (c) and Cdl (d) values obtained by using the EEC2 equivalent circuit for MAPTMS/TMOS-Ti6Al4V and MAPTMS/TMOS/DMTMSP-Ti6A14V sytems. Electrolyte: SBF. DMTMSP/ silane hybrid volumetric ratio $=0.9 \mathrm{~mL} / 20 \mathrm{~mL}$.

\section{Discussion}

The formation of an implant-tissue interface depends strongly on the biocompatibility and physicochemical properties of the implant material. Biocompatibility involves biological processes such as cytotoxicity [39], whereas bio-functionality relates to the cell attachment mechanism [40] including cell adhesion, spreading, morphology, migration, proliferation and differentiation [41, 42]. Osteoblast adhesion influences the proliferation and differentiation of bone cells, as well as the osseointegration of bone-implants; as such, it is of critical importance for biocompatibility of a material [41].

A major problem for Ti6Al4V alloy biocompatibility is the release of metal ions to the surrounding medium due to corrosion effects [4]. The MAPTMS/TMOS coating acts as a barrier to alloy corrosion, which inhibits the toxic influence of metal ions on the culture. The mechanism of DMTMSP's enhancement in biocompatibility is also likely to be an attribute of the coating's corrosion barrier effect, aided by the increased cross-linking within the sol-gel coating. 
Further to the proposed increase in barrier properties, the incorporation of DMTMSP into the film acts to modulate the surface functionality to a more attractive surface for cell culture. This modulation is observed in changes to the surface wetting properties, where surfaces with intermediate wetting properties are noted to enhance serum protein uptake and accordingly cell proliferation and viability [45]. This effect was previously observed with phosphorous incorporating films [20].

The corrosion protection results presented here are promising, despite the low values found for the $\mathrm{R}_{\text {coat }}$ parameter of these DMTMSP sol-gel when only one thin coat is applied, suggesting that these sol-gel formulations would not be suitable for the development of one layer thin film with high barrier properties for permanent prosthesis. As shown, this problem can be overcome by applying two sol-gel coats on the Ti6Al4V surface, which improves notably these barrier properties. Nevertheless, after proving the unique properties of these systems we believe the results obtained can guide the development of MAPTMS/TMOS/DMTMSP coatings based on a single coating layer, to be applied in the design of new coatings for control over the corrosion rate of biodegradable magnesium temporal implants, which is into an emerging research line of great interest $[46,47]$.

\section{Conclusion}

The incorporation of DMTMSP in the organic-inorganic hybrid based on a MAPTMS/TMOS mixture leads to the development of Si-O-P and $\mathrm{PO}_{4}{ }^{-3}$ units both of which indicate that the DMTMSP has been incorporated at a molecular level into the sol-gel network. Homogeneous, transparent and crack-free films have been obtained after incorporation of DMTMSP, thus these films can act as more effective physical barriers for chemically aggressive physiological environments. Although studies into corrosion resistance show that multilayer coatings are required for long-term exposures to physiological fluids or for possible application on permanent in-vivo implants. The presence of phosphorus at molecular level in the organicinorganic matrix, also results in enhancement of normal human osteoblast cytotoxicity/viability and adhesion in-vitro, providing systems with enhanced biocompatibility.

\section{CRediT authorship contribution statement}

A.A. El hadad: $\quad$ Methodology, Validation, Formal analysis, Investigation, Data Curation, Writing Original Draft 
F.R. García-Galván: Methodology, Validation, Formal analysis, Investigation, Data Curation, Writing Original Draft

M.A. Mezour: $\quad$ Conceptualization, Formal analysis, Writing - Original Draft

G.J. Hickman: Conceptualization, Methodology, Investigation, Resources, Data Curation, Writing Original Draft, Project administration

I. E. Soliman: $\quad$ Conceptualization, Formal analysis, Writing - Original Draft

A. Jiménez-Morales: Methodology, Formal analysis, Investigation, Resources

V. Barranco: $\quad$ Conceptualization, Methodology, Investigation, Data

Curation, Resources, Supervision, Writing Original Draft

J.C. Galván: $\quad$ Conceptualization, Methodology, Writing Original Draft, Supervision, Project administration, Funding acquisition

C.C. Perry: $\quad$ Conceptualization, Methodology, Writing Original Draft, Supervision, Project administration, Funding acquisition

\section{Declaration of Competing Interest}

The authors declare that they have no known competing financial interests or personal relationships that could have appeared to influence the work reported in this paper.

\section{Acknowledgements}

The authors would like to acknowledge financial support from the Ministry of Economy and Competitiveness of Spain (MAT2015-65445-C2-1-R Project).

\section{References}

1. R.W. Bucholz, Nonallograft osteoconductive bone graft substitutes, Clin. Orthop. Rel. Res., 395 (2002) 44-52.

2. M.A. Lorio, R. Rosa, J.F. Suarez, P. Ruiz, G. Ciancio, G.W. Burke, J.F. Camargo, Influence of immune activation on the risk of allograft rejection in human immunodeficiency virus-infected kidney transplant recipients, Transpl. Immunol., 38 (2016) 40-43.

3. R. Bosco, J.V. Beucken, S. Leeuwenburgh and J. Jansen, Surface Engineering for Bone Implants: A Trend from Passive to Active Surfaces, Coatings, 2(3) (2012) 95119.

4. Q. Chen, G.A. Thouas, Metallic implant biomaterials, Mater. Sci. Eng. R-Rep., 87 (2015) 1-57.

5. F. Bartolomeu, C.S. Abreu, C.G. Moura, M.M. Costa, N. Alves, F.S. Silva, G. Miranda, Ti6Al4V-PEEK multi-material structures - design, fabrication and tribological characterization focused on orthopedic implants, Tribol. Int., 131 (2019) 672-678. 
6. Y. Liu, S.W. Yao, H.B. Ke, Z.Y. Liu, Research on surface treatment technologies of Ti6Al4V alloys, Appl. Mech. Mater., 670-671 (2014) 569-572.

7. J.F. Flores-Álvarez, F.J. Rodríguez-Gómez, E. Onofre-Bustamante, J. GenescáLlongueras, Study of the electrochemical behavior of a Ti6Al4V alloy modified by heat treatments and chemical conversion, Surf. Coat. Technol., 315 (2017) 498-508.

8. M. Basiaga, W. Kajzer, W. Walke, A. Kajzer, M. Kaczmarek, Evaluation of physicochemical properties of surface modified Ti6A14V and Ti6Al7Nb alloys used for orthopedic implants, Mater. Sci. Eng. C-Mater. Biol. Appl., 68 (2016) 851-860.

9. M. Catauro, F. Bollino, R. Giovanardi, P. Veronesi, Modification of Ti6Al4V implant surfaces by biocompatible TiO2/PCL hybrid layers prepared via sol-gel dip coating: Structural characterization, mechanical and corrosion behaviour, Mater. Sci. Eng. CMater. Biol. Appl., 74 (2017) 501-507.

10. D. Velten, V. Biehl, F. Aubertin, B. Valeske, W. Possart, J. Breme, Preparation of $\mathrm{TiO}_{2}$ layers on cp-Ti and Ti6Al4V by thermal and anodic oxidation and by sol-gel coating techniques and their characterization, J. Biomed. Mater. Res., 59 (1) (2002) 18-28.

11. P. Judeinstein, C. Sanchez, Hybrid organic-inorganic materials: A land of multidisciplinarity, J. Mater. Chem. 6 (1996) 511-525.

12. C. Sanchez, B. Julián, P. Belleville, M. Popall, Applications of hybrid organicinorganic nanocomposites. J. Mater. Chem. 15 (35-36) (2005) 3559-3592.

13. M. Catauro, F. Bollino, F. Papale, C. Ferrara, P. Mustarelli, Silica-polyethylene glycol hybrids synthesized by sol-gel: Biocompatibility improvement of titanium implants by coating, Mater. Sci. Eng. C - Biomimetic Supramol. Syst. 55 (2015) 118-125.

14. M. Catauro, F. Bollino, R. Giovanardi, P. Veronesi, Modification of Ti6Al4V implant surfaces by biocompatible TiO2/PCL hybrid layers prepared via sol-gel dip coating: Structural characterization, mechanical and corrosion behaviour, Mater. Sci. Eng. CBiomimetic Supramol. Syst. 74 (2017) 501-507.

15. J.C.B. Alcázar, R.M.J. Lemos, M.C.M. Conde, L.A. Chisini, M.M.S. Salas, B.S. Noremberg, F.V.D. Motta, F.F. Demarco, S.B.C. Tarquinio, N.L.V., Carreño, Preparation, characterization, and biocompatibility of different metal oxide/PEGbased hybrid coating synthesized by sol-gel dip coating method for surface modification of titanium, Prog. Org. Coat. 130 (2019) 206-213.

16. J. Ballarre, D.A. López, W.H. Schreiner, A. Durán, S. M. Cere, Protective hybrid solgel coatings containing bioactive particles on surgical grade stainless steel: Surface characterization. Appl. Surf. Sci. 253 (2007) 7260-7264.

17. S.V. Harb, M.C. Uvida, A. Trentin, A. Oliveira Lobo, T.J. Webster, S.H. Pulcinelli, C.V. Santilli, P. Hammer, PMMA-silica nanocomposite coating: Effective corrosion protection and biocompatibility for a Ti6Al4V alloy, Mater. Sci. Eng. C - Biomimetic Supramol. Syst. 110 (2020) 110713.

18. A.A. El Hadad, E. Peón, F.R. García-Galván, V. Barranco, J. Parra, A. JiménezMorales, J.C. Galván, Biocompatibility and corrosion protection behaviour of hydroxyapatite sol-gel-derived coatings on Ti6Al4V alloy, Materials 10 (2), (2017) 94.

19. A. A. El hadad, V. Barranco, A. Jiménez-Morales, E. Peón, G. J. Hickman, C.C. Perry and J. C. Galván, Enhancing in-vitro biocompatibility and corrosion protection of 
organic-inorganic hybrid sol-gel films with nanocrystalline hydroxyapatite, J. Mater. Chem. B, 2 (24) (2014) 3886-3896.

20. A.A. El hadad, V. Barranco, A. Jiménez-Morales, G.J. Hickman, J.C. Galván, C.C. Perry, Triethylphosphite as a network forming agent enhances in-vitro biocompatibility and corrosion protection of hybrid organic-inorganic sol-gel coatings for Ti6Al4V alloys, J. Mater. Chem. B, 2 (45) (2014) 7955-7963.

21. G. Repetto, A. del Peso, J.L. Zurita, Neutral red uptake assay for the estimation of cell viability/cytotoxicity, Nat. Protoc., 3 (7) (2008) 1125-1131.

22. T. Kokubo, H. Kushitani, S. Sakka, T. Kitsugi, T. Yamamuro, Solutions able to reproduce in vivo surface-structure changes in bioactive glass-ceramic A-W ${ }^{3}, J$. Biomed. Mater. Res., 24 (6) (1990) 721-734.

23. D. Johnson, Zview for Windows: A software Program for EIS Analysis, Scribner Associates Inc.@, NC, USA, 1990-2017.

24. S. Z. Yu, T. K. S. Wong, X. Hu and K. Pita, The Effect of TEOS/MTES Ratio on the Structural and Dielectric Properties of Porous Silica Films, J. Electrochem. Soc., 150 (5) (2003) F116-F121.

25. N. Nishiyama, K. Horie, T. Asakura, Hydrolysis and condensation mechanisms of a silane coupling agent studied by ${ }^{13} \mathrm{C}$ and ${ }^{29} \mathrm{Si}$ NMR, J. Appl. Polym. Sci., 34 (4) (1987) 1619-1630.

26. C. Jing, J. Hou, Sol-gel-derived alumina/polyvinylpyrrolidone hybrid nanocomposite film on metal for corrosion resistance, J. Appl. Polym. Sci., 105 (2) (2007) 697-705.

27. A.A. El hadad, D. Carbonell, V. Barranco, A. Jiménez-Morales, B. Casal, J.C. Galván, Preparation of sol-gel hybrid materials from $\gamma$ methacryloxypropyltrimethoxysilane and tetramethyl orthosilicate: Study of the hydrolysis and condensation reactions, Colloid Polym. Sci., 289 (17-18) (2011) 18751883.

28. Q. Chen, N. Miyata, T. Kokubo, T. Nakamura, Bioactivity and mechanical properties of PDMS-modified $\mathrm{CaO}-\mathrm{SiO}_{2}-\mathrm{TiO}_{2}$ hybrids prepared by sol-gel process, J. Biomed. Mater. Res., 51 (4) (2000) 605-611.

29. H. Niida, M. Takahashi, T. Uchino, T. Yoko, Preparation and structure of organicinorganic hybrid precursors for new type low-melting glasses, J. Non-Cryst. Solids, 306 (3) (2002) 292-299.

30. A. Dalmau, V. Guiñón Pina, F. Devesa, V. Amigó, A. Igual Muñoz, Influence of fabrication process on electrochemical and surface properties of Ti-6Al-4V alloy for medical applications, Electrochim. Acta, 95 (2013) 102-111.

31. L. Beaunier, I. Epelboin, J.C. Lestrade, H. Takenouti, Etude électrochimique et par microscopie électronique a balayage du fer recouvert de peinture, Surf. Technol., 4 (3) (1976) 237-254.

32. M.C.S.S. Macedo, I.C.P. Margarit-Mattos, F.L. Fragata, J.B. Jorcin, N. Pébère, O.R. Mattos, Contribution to a better understanding of different behaviour patterns observed with organic coatings evaluated by electrochemical impedance spectroscopy, Corr. Sci., 51 (6) (2009) 1322-1327.

33. A. Dalmau, V. Guiñón Pina, F. Devesa, V. Amigó, A. Igual Muñoz, Electrochemical behavior of near-beta titanium biomedical alloys in phosphate buffer saline solution, Mater. Sci. Eng. C-Mater. Biol. Appl., 48(2015) 55-62. 
34. C.H. Hsu, F. Mansfeld, Concerning the Conversion of the Constant Phase Element Parameter Y0 into a Capacitance, Corrosion, 57 (2001) 747-748.

35. B. Hirschorn, M.E. Orazem, B. Tribollet, V. Vivier, I. Frateur, M. Musiani, Determination of effective capacitance and film thickness from constant-phaseelement parameters, Electrochim. Acta, 55 (21) (2010) 6218-6227.

36. M.E. Orazem, I. Frateur, B. Tribollet, V. Vivier, S Marcelin, N Pébère, A.L. Bunge, E.A. White, D.P. Riemer, M. Musiani, Dielectric Properties of Materials Showing Constant-Phase-Element (CPE) Impedance Response, J. Electrochem. Soc., 160 (6) (2013) C215-C225.

37. F. Deflorian, L. Fedrizzi, S. Rossi, P.L. Bonora, Organic coating capacitance measurement by EIS: ideal and actual trends, Electrochim. Acta, 44 (24) (1999) 4243 4249.

38. A. Miszczyk K. Darowicki, Water uptake in protective organic coatings and its reflection in measured coating impedance, Prog. Org. Coat., 124 (2018) 296-302.

39. H. Babich, E. Borenfreund, Applications of the neutral red cytotoxicity assay to in vitro toxicology, ATLA-Altern. Lab. Anim., 18, (1990) 129-144.

40. H. Schweikl, R. Müller, C. Englert, K.-A. Hiller, R. Kujat, M. Nerlich, G. Schmalz, Proliferation of osteoblasts and fibroblasts on model surfaces of varying roughness and surface chemistry, J. Mater. Sci.-Mater. Med., 18(10) (2007) 1895-1905.

41. K. Anselme, Biomaterials, Osteoblast adhesion on biomaterials, Biomaterials, 21 (7) (2000) 667-681.

42. K. Anselme, M. Bigerelle, Modelling approach in cell/material interactions studies, Biomaterials, 27 (8) (2006) 1187-1199.

43. A. Piegari, E. Masetti, Thin film thickness measurement: A comparison of various techniques, Thin Solid Films, 124 (1985) 249-257.

44. S. Agarwal, J. Curtin, B. Duffy, S. Jaiswal, Biodegradable magnesium alloys for orthopaedic applications: A review on corrosion, biocompatibility and surface modifications, Mater. Sci. Eng. C-Mater. Biol. Appl., 68 (2016) 948-963.

45. M-S. Song, R-C. Zeng, Y-F Ding, R. W. Li, M. Easton, I. Cole, N. Birbilis, X-B. Chen. Recent advances in biodegradation controls over $\mathrm{Mg}$ alloys for bone fracture management: A review, J. Mater. Sci. Technol., 35 (4) (2019) 535-544. 


\section{Figure legends}

Figure 1. (a) TGA of the prepared MAPTMS/TMOS hybrids containing increasing amounts of DMTMSP. (b) ATR-IR spectra of the MAPTMS/TMOS/ DMTMSP -Ti6Al4V system for coatings containing different content of DMTMSP. (c) Solid state ${ }^{29} \mathrm{Si}-\mathrm{NMR}$ spectra of MAPTMS/TMOS silane hybrids containing 0.0, 0.6 and $0.9 \mathrm{~mL}$ of DMTMSP.

Figure 2. Variation in the thickness of the MAPTMS/TMOS silane hybrid coatings as a function of the DMTMSP content $(0.0,0.3,0.6$ and $0.9 \mathrm{~mL})$.

Figure 3. (a) Neutral red proliferation/cytotoxicity assay for NHOst cultured on un-coated Ti6Al4V, MAPTMS/TMOS-Ti6Al4V system (control) and silane hybrid coatings containing DMTMSP (0.3 and $0.9 \mathrm{~mL})$ after a 7 -day period. (b) Fluorescence micrographs of NHOst cells growing on un-coated Ti6Al4V and coated surfaces and stained for the presence of vinculin (green), f-actin (red) and nuclei (blue). Arrows highlight regions where focal adhesion is observed between cell and surface.

Figure 4. (a, b) Impedance Nyquist plots obtained for an uncoated Ti6Al4V sample and for two Ti6Al4V samples coated with one layer and two layers of the MAPTMS/TMOS silane mixture containing DMTMSP $(0.9 \mathrm{~mL})$. (c, d) The same impedance data in Bode representation. Immersion time in SBF: 1 day.

Figure 5. Equivalent circuits EEC1, EEC2 and EEC3 used for fitting and modelling the experimental impedance data of the studied systems.

Figure 6. Nyquist plots, represented in two different scales [(a) and (b)] and Bode plots [(c) and (d)] obtained for an uncoated Ti6A14V sample and Ti6A14V samples coated with one layer of DMTMSP sol-gel thin films with different volumetric ratios of DMTMSP: $0 \mathrm{~mL}$ (blank sample), $0.3 \mathrm{~mL}, 0.6 \mathrm{~mL}$ and $0.9 \mathrm{~mL}$ per $20 \mathrm{~mL}$ of MAPTMS/TMOS silane mixture respectively. Electrolyte: SBF. Immersion time: 1 day.

Figure 7. Evolution of the Rcoat (a), Ccoat (b), Rct (c) and Cdl (d) values obtained by using the EEC2 equivalent circuit for MAPTMS/TMOS-Ti6A14V and MAPTMS/TMOS/DMTMSPTi6Al4V sytems. Electrolyte: $\mathrm{SBF}$. DMTMSP/ silane hybrid volumetric ratio $=0.9 \mathrm{~mL} / 20$ $\mathrm{mL}$. 